\title{
Penicillamine-induced myasthenia in rheumatoid arthritis: its clinical and genetic features
}

\author{
J. P. DELAMERE, ${ }^{1}$ S. JOBSON,${ }^{2}$ L. P. MACKINTOSH,${ }^{2}$ L. WELLS,${ }^{2}$ AND K. W . \\ WA LTON ${ }^{1}$ \\ From the ${ }^{1}$ Department of Investigative Pathology, the Medical School, Birmingham University, and the \\ ${ }^{2}$ Regional Blood Transfusion Service, Birmingham
}

SUMmARY The clinical features and genetic background of 18 patients with rheumatoid arthritis were investigated following the development of penicillamine-induced myasthenia (PIM). The initial myasthenic symptoms in all patients consisted of variable diplopia and/or ptosis with progression to a more generalised involvement in 7 of them. No clinical, humoral, or genetic factor was determined which would allow identification of individuals developing generalised as opposed to ocular myasthenia. Withdrawal of penicillamine was associated over 4-60 weeks with a slow resolution of symptoms, facilitated in 12 patients by the use of anticholinesterase agents. In 2 patients a persistent partial unilateral ptosis remains after 15 and 25 months, while in a further patient diplopia is present $\mathbf{4 2}$ months after resolution of the other myasthenic symptoms. The patients with PIM when compared with a healthy 'control' population had a significant increase in HLA Dr1 ( $p$ corr $<0.005$ ) and an absence of HLA Dr 3. A genetic susceptibility to the development of PIM, distinct from that observed in myasthenia gravis of spontaneous onset, is suggested by this abnormal distribution of HLA Dr antigens.

Myasthenia is a recognised, albeit uncommon, complication of penicillamine therapy. ${ }^{1}$ The majority of cases of this supposedly immune-mediated side effect have arisen when penicillamine is employed in the treatment of rheumatoid arthritis. ${ }^{1}$ However, isolated cases have occurred in association with the treatment of Wilson's disease, ${ }^{2}{ }^{3}$ progressive systemic sclerosis, $^{4}$ and primary biliary cirrhosis. ${ }^{5}$ Penicillamine-induced myasthenia (PIM), while being dependent on penicillamine for its development and progression, ${ }^{1}$ closely resembles spontaneous-onset myasthenia gravis clinically and in the accompanying presence of antibodies directed against acetylcholine receptors and/or striated muscle. ${ }^{6}$

The role of constitutional factors in the aetiology of spontaneous-onset myasthenia gravis and the development of immune-mediated manifestations of drug toxicity has recently aroused great interest. A genetic predisposition to the development of hydralazine-induced systemic lupus erythematosus, ${ }^{7}$ parenteral gold-induced nephropathy, ${ }^{8}$ and spontaneous-onset myasthenia gravis when as-

Accepted for publication 6 August 1982.

Correspondence to Dr J. P. Delamere, Department of Investigative Pathology, Rheumatism Research Wing, The Medical School, University of Birmingham, Birmingham B15 2TJ. sociated with thymic hyperplasia ${ }^{9-11}$ has been inferred from the abnormal distribution of HLA antigens observed in these 3 pathological states.

We have investigated the possibility that a genetic factor, determined by a locus or loci situated within the major histo-compatibility complex (MHC) of chromosome 6 , might influence the development and/or expression of PIM. The HLA A, B, and Dr type together with the alleles of the complement components $\mathrm{C} 2, \mathrm{C} 4$, and factor $\mathrm{B}$ (which are controlled by loci in close proximity to those of HLA B and Dr) were ascertained in patients with rheumatoid arthritis who had developed a penicillaminedependent myasthenia.

\section{Patients and methods}

Eighteen previously unreported Caucasian patients (4M:14F) who developed PIM during the period August 1978 to December 1981 were studied. All suffered with classical or definite rheumatoid arthritis as defined by the American Rheumatism Association criteria. Patient data together with details of penicillamine therapy and duration of rheumatoid arthritis at the onset of myasthenic symptoms appear in Table 1. 
Table 1 Patient data. Penicillamine therapy and duration of rheumatoid arthritis $(R A)$ at the onset of myasthenia.

\begin{tabular}{rrlrrr}
\hline Subject & $\begin{array}{c}\text { Age } \\
(y r)\end{array}$ & Sex & $\begin{array}{c}\text { Duration } \\
\text { of } R A(y r)\end{array}$ & \multicolumn{2}{c}{ Penicillamine therapy } \\
\cline { 5 - 6 } & & & & $\begin{array}{c}\text { Duration } \\
\text { (months) }\end{array}$ & $\begin{array}{c}\text { Dosage } \\
(\mathbf{m g})\end{array}$ \\
\hline 1 & 54 & F & 5 & 11 & 250 \\
2 & 55 & F & 10 & 12 & 500 \\
3 & 64 & F & 10 & 21 & 500 \\
4 & 46 & F & 7 & 3 & 250 \\
5 & 36 & M & 4 & 7 & 750 \\
6 & 56 & F & 18 & 27 & 250 \\
7 & 46 & F & 4 & 8 & 750 \\
8 & 39 & F & 3 & 32 & 250 \\
9 & 42 & M & 4 & 22 & 375 \\
10 & 67 & F & 7 & 8 & 250 \\
11 & 64 & F & 3 & 22 & 250 \\
12 & 54 & F & 34 & 5 & 500 \\
13 & 57 & F & 7 & 54 & 625 \\
14 & 61 & M & 10 & 24 & 500 \\
15 & 47 & F & 7 & 6 & 500 \\
16 & 53 & M & 3 & 9 & 1500 \\
17 & 53 & F & 12 & 24 & 1000 \\
18 & 53 & F & 4 & 12 & 250 \\
\hline
\end{tabular}

Myasthenia. The clinical diagnosis of myasthenia was substantiated by a rapid transient improvement in the myasthenic symptoms and signs following the intravenous administration of edrophonium chloride. Chest radiography was performed in an attempt to exclude the presence of a thymoma. Antiacetylcholine receptor antibodies were determined by the iodinated $\alpha$-bungarotoxin assay, ${ }^{12}$ and rat striatal muscle was employed as substrate for the detection of anti-striated-muscle antibodies by indirect immunofluorescence.

HLA and complement typing. The HLA antigens at the A, B, and Dr loci were determined by the standard 7th Histocompatibility Workshop microcytotoxicity technique. ${ }^{13}$ Serum, which had been stored at $-70^{\circ} \mathrm{C}$ and thawed immediately prior to analysis, was used to determine the alleles of the complement components $\mathrm{C} 4^{14}$ and factor $\mathrm{B}(\mathrm{Bf})^{15}$ by the method of agarose electrophoresis followed by immunofixation. The alleles of complement $\mathrm{C} 2$ were obtained by isoelectric focusing as described by Meo et al. ${ }^{16}$

Statistical methods. Significance was determined by

Table 2 Initial and subsequent myasthenic symptoms and signs together with their duration.

\begin{tabular}{|c|c|c|c|}
\hline \multirow[t]{2}{*}{ Subject } & \multicolumn{2}{|c|}{ Myasthenic symptoms and signs } & \multirow[t]{2}{*}{ Period of resolution } \\
\hline & Initial & Subsequent & \\
\hline 1 & Diplopia and ptosis & None & $\begin{array}{l}17 \text { Months, incomplete } \\
\text { (persisting partial (L) ptosis) }\end{array}$ \\
\hline 2 & Diplopia and ptosis & None & 2 Months, complete \\
\hline 3 & Diplopia & $\begin{array}{l}\text { Ptosis, slurred speech, } \\
\text { neck and shoulder girdle } \\
\text { weakness }\end{array}$ & 4 Months, complete \\
\hline 4 & Ptosis & $\begin{array}{l}\text { Generalised weakness, } \\
\text { slurred speech }\end{array}$ & 2 Months, complete \\
\hline 5 & Diplopia & $\begin{array}{l}\text { Ptosis generalised } \\
\text { weakness, dyspnoea }\end{array}$ & 2 Months, complete \\
\hline 6 & Diplopia and ptosis & generalised weakness & 4 Months, complete \\
\hline 7 & Diplopia and ptosis & None & 1 Month, complete \\
\hline 8 & Ptosis & $\begin{array}{l}\text { Shoulder girdle weakness } \\
\text { slurred speech }\end{array}$ & 6 Months, complete \\
\hline 9 & Diplopia & Ptosis, slurred speech & 3 Months, complete \\
\hline 10 & Ptosis & None & $\begin{array}{l}24 \text { Months, incomplete } \\
\text { (persisting partial (R) ptosis) }\end{array}$ \\
\hline 11 & Diplopia & $\begin{array}{l}\text { Ptosis, weakness jaw } \\
\text { and neck. Dyspnoea }\end{array}$ & 15 Months, complete \\
\hline 12 & Diplopia and ptosis & None & Awaited \\
\hline 13 & Diplopia and ptosis & None & Awaited \\
\hline 14 & Diplopia and ptosis & None & Awaited \\
\hline 15 & Diplopia and ptosis & $\begin{array}{l}\text { Cervical and shoulder } \\
\text { girdle weakness }\end{array}$ & Awaited \\
\hline 16 & Diplopia and ptosis & None & 8 Months, complete \\
\hline 17 & Diplopia & Slurred speech & $\begin{array}{l}18 \text { Months, incomplete } \\
\text { (persisting diplopia) }\end{array}$ \\
\hline 18 & Diplopia and ptosis & None & 5 Months, complete \\
\hline
\end{tabular}


the chi-square test with Yates's correction. The corrected probability ( $p$ corr) was obtained by multiplying the uncorrected probability $(p)$ by the number of antigens sought at that particular HLA locus (i.e. in the case of HLA Dr $p$ corr $=p \times 9$ ).

\section{Results}

\section{CLINICAL FEATURES}

The initial and subsequent myasthenic symptoms and signs, which were not accompanied by any radiographic evidence of a thymoma, are illustrated in Table 2. Owing to delays in both presentation and diagnosis penicillamine therapy was continued after the initial onset of PIM for a period of 1-96 weeks (mean 12 weeks). During this time progression to more generalised myasthenia occurred in 7 patients, 2 of whom (patients 5 and 11) had involvement of the muscles of respiration. The initial myasthenic symptoms and signs in the remaining 11 patients persisted essentially unchanged, although they continued to receive penicillamine for 2-96 weeks (mean 16 weeks). In 2 patients (nos. 12 and 14), whose presenting features of diplopia and ptosis had persisted, but not progressed, for 1 and 3 months respectively the dosage of penicillamine was decreased but not discontinued as in the other 16 patients, 12 of whom required treatment with anticholinesterase agents. In the 14 patients who were studied for 4 months or more after presentation complete and permanent resolution of all myasthenic features occurred in 11 (Table 2). In the remaining 3 patients (nos. 1, 10 and 17) a persistent partial ptosis remained in 2 subjects (nos. 1 and 10) and diplopia in the third. Subjectively, penicillamine therapy was associated in all patients with a marked improvement in rheumatoid disease activity, which remained unaltered at the onset of myasthenia. Concomitant with this onset one patient (no. 8) developed a systemic lupus erythematosus-like syndrome with an antinuclear factor (ANF) titre 1/2560 and anti-DNA antibodies of 55 units $/ \mathrm{ml}$ (normal range $<25$ units $/ \mathrm{ml}$ ), while a further patient (no. 2) developed histologically confirmed hepatotoxicity. Both these toxic side effects, along with PIM, resolved spontaneously on withdrawal of penicillamine. In the 17 subjects tested, antibodies directed against acetylcholine receptors and striatal muscle were present in 17 and 4 respectively.

\section{HLA AND COMPLEMENT TYPING}

The frequency of the HLA B and Dr antigens in both the patients studied and in two 'local' control populations are illustrated in Tables 3 and 4 . Minor differences in the distribution of the HLA B antigens, in particular HLA B27, were detected in the PIM
Table 3 Incidence of HLA B antigens in study group and Birmingham control population

\begin{tabular}{llc}
\hline $\begin{array}{l}\text { HLA B } \\
\text { antigen }\end{array}$ & $\begin{array}{l}\text { Study series } \\
\text { (18 subjects) }\end{array}$ & $\begin{array}{l}\text { Control } \\
\text { population } \\
\text { (380 subjects) }\end{array}$ \\
\hline B5 & $1(6 \%)$ & $36(9 \%)$ \\
B7 & $4(22 \%)$ & $125(33 \%)$ \\
B8 & $5(28 \%)$ & $114(30 \%)$ \\
B12 & $8(44 \%)$ & $132(35 \%)$ \\
B13 & $1(6 \%)$ & $11(3 \%)$ \\
B14 & $0(0 \%)$ & $20(5 \%)$ \\
B15 & $1(6 \%)$ & $41(11 \%)$ \\
B16 & $2(11 \%)$ & $20(5 \%)$ \\
B17 & $1(6 \%)$ & $32(8 \%)$ \\
B 18 & $1(6 \%)$ & $20(5 \%)$ \\
Bw21 & $1(6 \%)$ & $9(2 \%)$ \\
Bw22 & $0(0 \%)$ & $11(3 \%)$ \\
B27 & $5(28 \%)$ & $32(8 \%)$ \\
Bw35 & $2(11 \%)$ & $40(10 \%)$ \\
B37 & $0(0 \%)$ & $6(1 \%)$ \\
B40 & $1(6 \%)$ & $40(10 \%)$ \\
\hline
\end{tabular}

Table 4 Incidence of HLA Dr antigens in study group and Birmingham control population.

\begin{tabular}{lll}
\hline $\begin{array}{l}\text { HLA Dr } \\
\text { antigen }\end{array}$ & $\begin{array}{l}\text { Study series } \\
\text { (16 subjects) }\end{array}$ & $\begin{array}{l}\text { Control } \\
\text { population } \\
\text { (59 subjects) }\end{array}$ \\
\hline Dr 1 & $10(62 \%)^{*}$ & $10(17 \%)$ \\
Dr 2 & $3(19 \%)$ & $18(30 \%)$ \\
Dr 3 & 0 & $18(30 \%)$ \\
Dr 4 & $5(31 \%)$ & $13(22 \%)$ \\
Dr 5 & 0 & $6(10 \%)$ \\
Drw 6 & $2(12 \%)$ & $8(13 \%)$ \\
Dr 7 & $6(37 \%)$ & $15(25 \%)$ \\
Drw 8 & 0 & $1(2 \%)$ \\
Dr w 9 & $1(6 \%)$ & $5(8 \%)$ \\
\hline
\end{tabular}

"HLA DR I significantly increased in study population ( $\mathrm{p}$ corr $<0.005)$.

patients compared with the control group. However, none of these was statistically significant. It proved technically impossible in subjects 4 and 9 to obtain a satisfactory HLA Dr type. In the remaining 16 patients there was a significant increase in HLA Dr 1 (62\% PIM; $17 \%$ controls; $p$ corr $<0.005$ ) and an absence of HLA Dr 3. Complement typing in the 16 subjects investigated showed 13 to be homozygous for the electrophoretically 'slow' allele of complement factor B (BfSS), 2 patients (no. 3 and 7), both of whom were HLA B8, were homozygous for the 'fast' allele (BfFF), and patient 6 (HLA B7B18) was heterozygous (BfFS). No abnormal distribution of the alleles of the complement components $\mathrm{C} 2$ and $\mathrm{C} 4$ was found. 


\section{Discussion}

The aetiology of this distressing and occasionally fatal manifestation of penicillamine toxicity remains obscure. However, the suggestion that penicillamine might in some undetermined manner unveil latent myasthenia gravis has been the subject of debate. ${ }^{17-20}$ The data arising from our study do not support this suggestion. HLA typing in the PIM subjects revealed a significant increase in HLA Dr 1 and an absence of HLA Dr 3. These findings argue that subjects developing PIM possess a different genetic background from those suffering spontaneous-onset myasthenia (in the absence of a thymoma), where the incidence of HLA Dr 3 is increased and that of HLA Dr 1 is normal. ${ }^{9-11}$ They also appear to differ genetically from Caucasian rheumatoid patients in general, in whom HLA Dr 4 is increased but the incidence of HLA Dr 1 is unaltered. ${ }^{21-23}$

The literature contains reports of 6 other cases of PIM complicating rheumatoid arthritis in which HLA A, B, and Dr typing has been performed. ${ }^{62024}{ }^{25}$ Four cases were HLA Dr 1, while one was HLA Dr $3 .^{20}$ The myasthenia in this last case was, however, atypical in the absence of antiacetylcholine receptor antibodies and, more importantly, in the recurrence of myasthenia 6 months after its initial complete resolution and 8 months after penicillamine had been withdrawn, a course that makes a druginduced aetiology unlikely. The absence of HLA Dr 3 in our study might reflect the increase in HLA Dr 1 which was observed in $62 \%$ of our patients as compared with $17 \%$ of controls. An alternative explanation for this apparent loss of the normal linkage disequilibrium between HLA B8 and Dr 3 would be the conferment of resistance to the development of PIM by the HLA B8 Dr 3 haplotype.

Two of our 5 HLA B8 subjects were BfFF, as opposed to none of 100 normal HLA B8 subjects investigated by Arnason et al. ${ }^{26}$ This confirms either that there has been a recombination of the known allelic association, or that we have detected an unusual MHC haplotype.

The initial myasthenic symptoms and signs observed in this study together with their progression and association with other manifestations of penicillamine toxicity are similar to the findings reported by others. ${ }^{17}$ Unfortunately we detected no clinical, serological, or genetic marker which would allow early differentiation between the group of 7 patients who developed generalised symptoms and the 11 whose initial myasthenic features remained essentially unchanged, even though penicillamine therapy was continued in some cases for several months. Owing to this inability to prognosticate between progressive and nonprogressive cases, discontinuation of penicillamine at the onset of symptoms, with or without the use of anticholinesterase agents, is the recommended regimen. Pencillamine usage was nevertheless associated with a striking improvement in rheumatoid disease activity. In view of this and the late presentation of the majority of patients with solely ocular symptoms, a closely monitored trial of decreasing dosage, rather than discontinuance of penicillamine, has been instituted in 2 patients with nonprogressive ocular myasthenia. It is too early to comment on the results of this modified therapy.

Although a genetic susceptibility to the development of PIM, based on the increased incidence of HLA Dr 1 and/or absence of HLA Dr 3, requires to be substantiated, these results strongly suggest that a different genetic background characterises druginduced as opposed to spontaneous-onset myasthenia. It is worth noting that an absence of HLA Dr 3 has been observed in another example of druginduced autoimmunity. Batchelor et al. ${ }^{7}$ found none of 26 patients with hydralazine-induced systemic lupus erythematosus to be HLA Dr 3 positive. In a preliminary report on rheumatoid patients who developed gold- or penicillamine-induced thrombocytopenia Panayi et al. ${ }^{27}$ found the HLA Dr 3 antigen to be present in all 7 patients who developed a rapid fall in platelets but absent in 10 who suffered a more gradual decline in the platelet count. But the mechanisms underlying the thrombocytopenia were not defined. The fascinating possibility that the HLA B8 $\mathrm{Dr} 3$ haplotype might predispose to spontaneous-onset autoimmune disorders while offering resistance to their drug-induced counterparts warrants further investigation.

We thank the following consultant physicians for kindly allowing us to study their patients: Dr R. B. Clague, Dr D. D. Felix Davies, Dr J. Hawkes, Dr P. Hillenbrand, Dr K. Lloyd-Jones, Dr J. Milles, Dr C. Murray-Leslie, Dr M. Webley, Dr J. Woodland, Dr G. Zaphiropoulos, and Dr A. Zalin.

Dr J P. Delamere is financially supported by an Arthritis and Rheumatism Council Cinical Research Fellowship.

\section{References}

1 Bucknall R C. Myasthenia associated with D-penicillamine therapy in rheumatoid arthritis. Proc $R$ Soc Med 1977; 70 (suppl 3): 114-7.

2 Czlonkowska A. Myasthenia syndrome during penicillamine treatment. Br Med J 1975; ii: 726-7.

3 Masters $\mathrm{C} \mathrm{L}$, Dawkins $\mathrm{R} \mathrm{L}$, Zilko $\mathrm{P} \mathrm{J}$, et al. Penicillamine-associated myasthenia gravis, antiacetylcholine receptor and antistriational antibodies. Am J Med 1977; 63: 689-94.

4 Torres C F, Griggs $\mathbf{R}$ C, Baum J, Penn A $S$. Penicillamine-induced myasthenia gravis in progressive systemic sclerosis. Arthritis Rheum 1980; 23: 505-8.

5 Matloff D S, Alpert E, Resnick R H, Koplan M M. A prospective trial of D-penicillamine in primary biliary cirrhosis. N Engl J Med 1982; 306: 319-26. 
6 Dawkins R L, Garlepp M J, McDonald B L, et al. Myasthenia gravis and D-penicillamine. J Rheumatol 1981; suppl 7: $169-74$.

7 Batchelor J R, Welsh $\mathrm{K} I$, Tinoco $R \mathrm{M}$, et al. Hydralazine-induced systemic lupus erythematosus: influence of HLA-Dr and sex on susceptibility. Lancet 1980; i: 1107-9.

8 Wooley P H, Griffin J, Panayi G S, et al. HLA-Dr antigens and toxic reaction to sodium aurothiomalate and D-penicillamine in patients with rheumatoid arthritis. $N$ Engl $J$ Med 1980; 303: 300-2.

9 Feltkamp T E W, Van Den Berg-Loonen P M, Nijenhuis L E, et al. Myasthenia gravis, autoantibodies and HLA antigens. $B r$ Med J 1974; i: 131-3.

10 Behan P O, Simpson J A, Dick H. Immune response genes in myasthenia gravis. Lancet 1973; it: 1033.

11 Dawkins R L. Myasthenia gravis. In: Bodmer W F, Batchelor J R, Bodmer J G, Festenstein H, Morris P J, eds. Histocompatibility testing 1977. Copenhagen: Munksgaard, 1978: 224-9.

12 Newson-Davis J, Pinching A J, Vincent A, Wilson S G. Function of circulating antibody to acetylcholine receptor in myasthenia gravis: investigation by plasma exchange. Neurology 1978; 28: 266-72.

13 Bodmer J G, Pickboume P, Richards S. Ia serology. In: Bodmer W F, Batchelor J R, Bodmer J G, Festenstein H, Morris P J, ed. Histocompatibility testing 1977. Copenhagen: Munksgaard 1978: 34-84.

14 Awdeh Z L, Alper C A. Inherited structural polymorphism of the fourth component of human complement. Proc Natl Acad Sci USA 1980; 77: 3576-80.

15 Alper C A, Boenisch T, Watson L. Genetic polymorphism in human glycine-rich beta-glycoprotein. J Exp Med 1972; 135: 68-80.

16 Meo T, Atkinson J, Bemoco M, Bernoco D, Ceppellini R. Mapping of the HLA locus controlling $\mathrm{C} 2$ structural variants and linkage disequilibrium between alleles $\mathrm{C} 2$ and $\mathrm{Bw} 15$. Eur J Immunol 1976; 6: 916-9.

17 Bucknall R C, Balint G, Dawkins R L. Myasthenia associated with D-penicillamine therapy in rheumatoid arthritis. Scand $J$ Rheumatol 1979; suppl 28: 91-3.

18 Gordan $R$ A, Burnside J W. D-penicillamine induced myasthenia gravis in rheumatoid arthritis. Ann Intern Med 1977; 87: 578-9.

19 Vincent A, Newson-Davis J, Martin V. Anti-acetylcholine receptor antibodies in D-penicillamine associated myasthenia gravis. Lancet 1978; i: 1254.

20 Bocanegra T, Espinoza L R, Vasey F B, Germain BF. Myasthenia gravis and penicillamine therapy of rheumatoid arthritis. JAMA 1980; 244: 1822-3.

21 Panayi G S, Wooley P, Batchelor J R. HLA-DRw 4 and rheumatoid arthritis. Lancet 1979; i: 730.

22 Panayi G S, Wooley P, Batchelor J R. Genetic basis of rheumatoid disease: HLA antigens, disease manifestations, and toxic reactions to drugs. Br Med J 1978; H: 1326-8.

23 Woodrow J C, Nichol F E, Zaphiropoulos G. DR antigens and rheumatoid arthritis: a study of two populations. Br Med J 1981; 283: 1287-8.

24 Lang A E, Humphrey J G, Gordon D A. Plasma exchange therapy for severe penicillamine-induced myasthenia gravis. $J$ Rheumatol 1981: 8: 303-7.

25 Keesey J, Novom S. HLA antigens in penicillamine-induced myasthenia gravis. Neurology 1979; 29: 528-9.

26 Arnason A, Larsen B, Marshall W H, et al. Very close linkage between HLA-B and Bf inferred from allelic association. Nature 1977; 268: 527-8.

27 Panayi G S. HLA antigens and adverse reactions to anti-rheumatic drugs. In: Maini $\mathbf{R} \mathbf{N}$, Berry $\mathbf{H}$, eds. Modulation of autoimmunity and disease. The penicillamine experience. Eastboume: Praeger, 1981: 65-9. 